\title{
Elderly Healthy Living Culture Connection With Rheumatic Disease Prevention Efforts In UPT Social Services Elderly And Young Children Binjai - Medan
}

\author{
Milna Chairunisa $1^{*}$, Heri Gultom ${ }^{2}$ \\ 1Prodi S1 Psikologi, Fakultas Kesehatan Masyarakat, Institut Kesehatan Helvetia, Medan \\ 2Prodi D3 Keperawatan, Fakultas Farmasi dan Kesehatan, Institut Kesehatan Helvetia, Medan \\ *Corresponding Author Email: milnachairunisa@helvetia.ac.id
}

\begin{abstract}
Background: Rheumatic disease not only attacks the joints, but also attack organs or other body parts. According to WHO (World Health Organization) estimates that approximately 335 million people worldwide suffer from rheumatic diseases. This number corresponds with the increase of elderly man and a variety of other health factors that are predicted to continue to increase in the future. It is estimated that approximately $25 \%$ of patients with rheumatic will experience a disability due to damage to the bone and joint disorders. Objective: aims to determine the relationship of culture of healthy living elderly with Rheumatic disease prevention efforts in UPT social services elderly and young children Binjai - Medan. Method: Terrain population in this study as many as 172 people. Based on the results of the bivariate analysis using analytical survey, which uses cross sectional method using primary data. Results indicate that the culture of healthy living in the poor category (7.7\%) and (51.3\%). Prevention of rheumatic disease in the good category (35.9\%) and the results can ( $p=0.674>$ 0.05), the Ha is rejected, Ho accepted. Conclusion: This shows there is no significant relationship between culture elderly healthy living and the prevention of rheumatic disease.
\end{abstract}

Keywords: Culture of Healthy Living and Prevention Rheumatism

\begin{abstract}
ABSTRAK
Latar Belakang: Penyakit reumatik tidak hanya menyerang sendi, tetapi juga menyerang organ tubuh atau bagian tubuh lainnya. Menurut WHO (World Health Organization) memperkirakan bahwa sekitar 335 juta orang di dunia mengidap penyakit reumatik. Jumlah ini sesuai dengan pertambahan manusia berusia lanjut dan beragam faktor kesehatan lainnya yang diprediksi akan terus mengalami peningkatan dimasa depan. Diperkirakan sekitar $25 \%$ penderita reumatik akan mengalami kecacatan akibat kerusakan pada tulang dan gangguan pada persendian. Tujuan: Penelitian ini bertujuan untuk mengetahui hubungan budaya hidup sehat lansia dengan upaya pencegahan penyakit Rematik di UPT pelayanan sosial lanjut usia dan anak balita wilayah Binjai - Medan. Metode: Populasi dalam penelitian ini sebanyak 172 orang, dan memiliki sampel sebanyak 39 responden. Berdasarkan hasil analisis bivariat menggunakan survei analitik, yang menggunakan metode cross sectional dengan menggunakan data sekunder. Hasil: penelitian ini menunjukan bahwa budaya hidup sehat dalam kategori diketahui bahwa dari 39 responden yang kurang sebanyak 3 orang $(7,7 \%)$ dan baik sebanyak 36 orang $(92,30 \%)$. dan hasil yang di dapat $(p=0,870>0,05)$, maka Ha ditolak, Ho diterima. Kesimpulan: Hal ini menunjukkan tidak ada hubungan yang bermakna antara budaya hidup sehat lansia dengan upaya pencegahan penyakit reumatik.
\end{abstract}

Kata kunci: Budaya Hidup Sehat, Upaya Pencegahan dan Reumatik 


\section{PENDAHULUAN}

Penyakit reumatik adalah penyakit yang tidak hanya menyerang sendi, tetapi juga menyerang organ tubuh atau bagian tubuh lainnya. Secara umum, defenisi reumatik adalah penyakit yang menyerang sendi atau struktur atau jaringan penunjang disekitar sendi. (Bawarodi, Rottie, \& Malara, 2017) Organisasi kesehatan di dunia World Health Organization (WHO) memperkirakan bahwa sekitar 335 juta orang di dunia mengidap penyakit reumatik. Jumlah ini sesuai dengan pertambahan manusia berusia lanjut dan beragam faktor kesehatan lainnya yang diprediksi akan terus mengalami peningkatan dimasa depan. (Putri, 2018)

Diperkirakan sekitar 25\% penderita reumatik akan mengalami kecacatan akibat kerusakan pada tulang dan gangguan pada persendian. Sekalipun belum ada angka pasti tentang jumlah penderita reumatik di Indonesia, diperkirakan hampir $80 \%$ penduduk yang berusia 40 tahun atau lebih menderita gangguan muskuluskletal, penyakit nyeri, kaku pada otot dan tulang. (Riska Ananda Saputri, Bau, \& Saranani, 2017)

Seiring bertambahnya usia, akan menyebabkan kondisi dan fungsi tubuh semakin menurun, sehingga usia lanjut akan mengalami beberapa keluhan masalah kesehatan. Beberapa masalah kesehatan yang umumnya dialami usia lanjut yaitu penyakit persendihan dan tulang, misalnya reumatik, osteoporosis, penyakit kardio vaskuler, misalnya penyakit jantung koroner, hipertensi, kolesterolemia dan lainlain,penyakit pencernaan, misalnya gastritis, penyakit metabolik, misalnya Diabetes Mellitus (DM), dan obesitas, penyakit pernafasan, misalnya asma dan TB paru, penyakit keganasan seperti kanker dan penyakit lainya seperti, pikun/dimensia, alzeimer, Parkinson, dan sebagainya. (Katuuk \& Wowor, 2018).

Dampak dari keadaan ini dapat mengancam jiwa penderitanya atau hanya menimbulkan gangguan kenyamanan dan masalah yang disebabkan oleh penyakit rematik tidak hanya berupa keterbatasan yang tampak jelas pada mobilitas hingga terjadi hal yang paling ditakuti yaitu menimbulkan kecacatan seperti kelumpuhan dan gangguan aktivitas hidup sehari-hari tetapi juga efek sistemik yang tidak jelas tetapi dapat menimbulkan kegagalan organ dan kematian atau mengakibatkan masalah seperti rasa nyeri, keadaan mudah lelah, perubahan citra diri serta resiko tinggi terjadi cidera. (Andri, Padila, Sartika, Putri, \& Harsismanto, 2020)

Berdasarkan hasil penelitian terakhir dari Zeng QY (2008), prevalensi nyeri rematik di Indonesia mencapai 23,6 hingga $31,3 \%$. Angka ini menunjukkan bahwa rasa nyeri akibat reumatik sudah cukup mengganggu aktivitas masyarakat indonesia, terutama mereka yang memiliki aktivitas.(Syam, 2016)

UPT Pelayanan Sosial Lanjut Usia Dan Anak Balita Wilayah Binjai - Medan merupakan salah satu Unit Pelaksana Teknis (UPT) adalah unsur pelaksana teknisyang berkedudukan di bawah dan bertanggung jawab kepada kepala dinas melalui wakil kepala dinas.UPT Pelayanan Sosial Lanjut Usia Dan Anak Balita Wilayah Binjai Medan dibentuk dan melaksanakan kegiatan berdasarkan hal berikut :UU No. 6 tahun 1974 tentang ketentuan-ketentuan pokok kesejahteraan sosial, UU No. 13 tahun 1998 tentang kesejahteraan lanjut usia, UU No. 32 tahun 2004 tentang pemerintahan daerah, Peraturan Pemerintah no.43 tahun 2004 tentang pelaksana upaya peningkatan 
kesejahteraan sosial lanjut usia, Keputusan MenteriSosial No.50/HUK/tahun 2004 tentang Perubahan Keputusan Menteri Kesehatan dan Kesejahteraan Sosial Nomor 193/KEMENSOS RI/III/2003 Tentang Standardisasi Sosial, Peraturan Daerah Nomor : 3 Tahun 2001 tanggal 21 Juli 2001, tentang Dinas di Provinsi Sumatera Utara.

Panti Werdha UPT Pelayanan Sosial Lanjut Usia dan Anak Balita Wilayah Binjai dan Medan adalah satu sarana pelayanan kesejahteraan sosial bagi para lanjut usia (jompo), khususnya bagi lanjut usia tidak mampu atau kurang beruntung. Warga Binaan Sosial (WBS) berjumlah 172 orang, diantaranya WBS laki-laki 81 orang dan WBS perempuan 91 orang dengan fasilitas 17 wisma. Kondisi lansia yang ada di UPT Pelayanan Sosial Lanjut Usia dan Anak Balita Wilayah Binjai dan Medan bermacammacam, ada yang tinggal keinginan sendiri ada yang di bawah oleh petugas, serta ada yang sehat, ada yang memiliki penyakit kronis, ada pula yang sudah mengalami demensia sehingga untuk melakukan aktifitas sehari-hari memerlukan bantuan dari petugas panti.

HASIL

\section{Analisis Univariat}

Tabel 1.

Distribusi Frekuensi Responden Berdasarkan Budaya Hidup Sehat Lansia dan Upaya Pencegahan Penyakit Reumatik

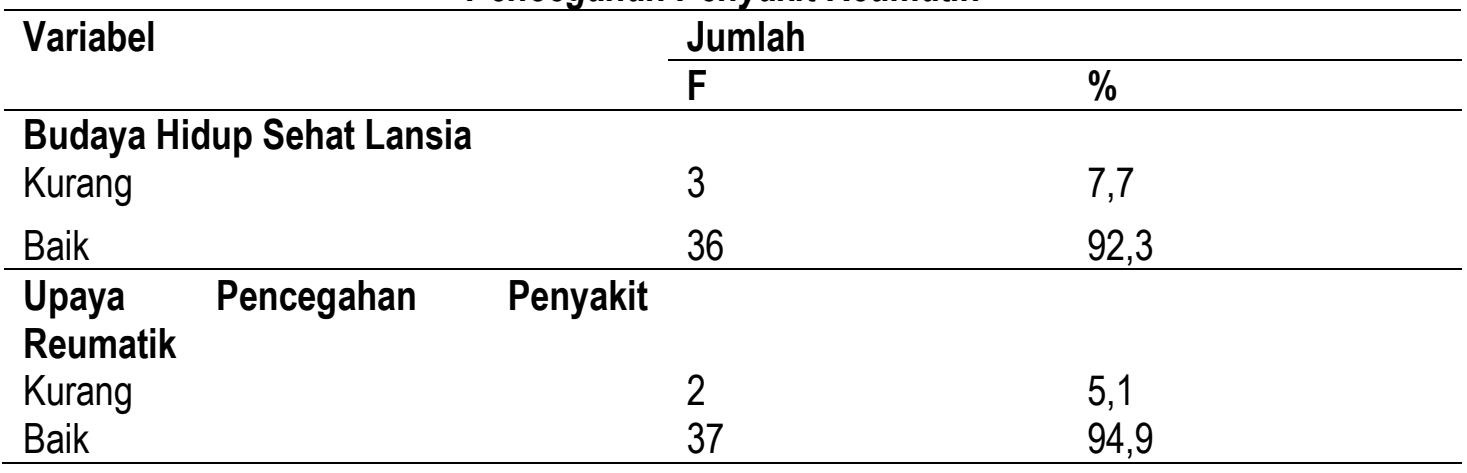
wawancara yang dilakukan peneliti di Panti Werda UPT Pelayanan Sosial Lanjut Usia dan Anak Balita Wilayah Binjai dan Medan survei awal peneliti mendapatkan 18 orang penderita reumatik. Dari survey awal tersebut di dapatkan penderita reumatik terdiri dari 12 orang perempuan dan 6 orang laki-laki.

\section{METODE}

Metode yang digunakan dalam penelitian ini adalah survey analitik dengan pendekatan cross sectional. Lokasi penelitian Ini dilakukan UPT Pelayanan Sosial Lanjut Usia \& Anak Balita, di Jalan. Perintis Kemerdekaan Gg. Sasana No.2 Kel. Cengkeh Turi Binjai. Populasi dalam penelitian ini adalah seluruh lansia (usia lanjut) yang berada di UPT pelayana sosial lanjut usia Binjai. Populasi penelitian ini berjumlah 90 orang. Teknik pengambilan sampel purposive sampling. Kriteria inklusi pengambilan sampel penelitian ini adalah anggota warga binaan sosial di UPT lanjut usia, berusia 60-70 tahun, dan memiliki penyakit reumatik.jumlah sampel yang ditentukan oleh peneliti sebanyak 39 orang. square. Uji statistik yang digunakan adalah chi- 
Hasil penelitian pada tabel 1. diperoleh distribusi frekuensi budaya hidup sehat lansia yang kurang sebanyak 3 orang $(7,7 \%)$ dan baik sebanyak 36 orang $(92,3 \%)$, upaya pencegahan penyakit reumatik di UPT pelayanan sosial lanjut usia dan anak balita wilayah buinjai medan diketahui bahwa dari 39 responden yang Frekuensi upaya pencegahan penyakit reumatik yang kurang sebanyak 2 orang $(5,1 \%)$ dan baik sebanyak 37 orang $(94,9 \%)$.

Analisa Bivariat

Tabel 2.

Distribusi Frekuensi Hubungan Budaya Hidup Sehat Lansia Dengan Upaya Pencegahan Penyakit Reumatik

\begin{tabular}{|c|c|c|c|c|c|c|c|}
\hline Variabel & \multicolumn{6}{|c|}{ Upaya Pencegahan Penyakit Reumatik } & \multirow{3}{*}{$P$} \\
\hline \multirow{2}{*}{$\begin{array}{l}\text { Budaya Hidup } \\
\text { Sehat Lansia }\end{array}$} & \multicolumn{2}{|c|}{ Kurang } & \multicolumn{2}{|c|}{ Baik } & \multicolumn{2}{|c|}{ Total } & \\
\hline & $\mathbf{F}$ & $\%$ & $f$ & $\%$ & $\mathbf{F}$ & $\%$ & \\
\hline Kurang & 0 & 0,00 & 3 & 7,70 & 3 & 7,7 & 0850 \\
\hline Baik & 2 & 5,1 & 34 & 87,2 & 36 & 92,3 & \\
\hline
\end{tabular}

Analisa bivariat digunakan untuk menyelidiki hubungan budaya hidup sehat lansia dengan upaya pencegahan penyakit reumatik di UPT Pelayanan Sosial Lanjut Usia Dan Anak Balita Wilayah Binjai dan Medan berat hasil analisis dapat diketahui pada tabel 2. diketahui bahwa dari 39 responden yang kurang sebanyak 3 orang $(7,7 \%)$ dan baik sebanyak 36 orang $(92,30 \%)$. Maka dapat diambil keputusan yaitu probabilitas (Asym Sing) yaitu variable budaya hidup sehat lansia $=0,850$ dari tingkat kesalahan 0,05. Berdasarkan kriteria tersebut berarti tidak ada hubungan budaya hidup sehat lansia dengan upaya pencegahan penyakit reumatik di UPT Pelayanan Sosial Lanjut Usia Dan Anak Balita Wilayah Binjai dan Medan.

\section{PEMBAHASAN}

\section{Budaya Hidup Sehat Lansia}

Berdasarkan hasil yang diperoleh diketahui bahwa mayoritas budaya hidup sehat lansia di UPT Pelayanan Sosial Lanjut Usia dan Anak Balita Wilayah Binjai dan Medan termasuk dalam kategori baik sebanyak 36 orang $(92,3 \%)$. Hal ini membuktikan bahwasanya pelayanan tenaga kesehatan, fasilitas yang sangat mendukung menyebabkan budaya hidup lansia baik.

Penelitian ini didukung oleh Meliny, Suhadi \& Sety (2018) yang menjelaskan bahwa pola makan responden sebagian besar kurang baik yakni $62,6 \%$. Respoden sering mengkonsumsi makanan tinggi purin seperti daging sapi, ikan, tempe, daun mlinjo, dan hasil laut. (Meliny \& Suhadi, 2018)

Gaya hidup adalah gambaran bagi setiap orang yang mengenakannya dan menggambarkan seberapa besar prilaku seseorang di dalam masyarakat. Distribusi frekuensi gaya hidup yang berkaitan dengan kebiasaan mengkonsumsi makanan yang mengandung purin tertinggi. Faktor yang mempengaruhi gaya hidup adalah konsumsi jeroan (60,6\%). Penderita rheumatoid arthritis dapat diberikan diet rendah purin. Purin termasuk protein golongan nukleoprotein. Penyebab penyakit rheumatoid arthritis dapat terjadi akibat penimbunan asam urat pada persendian tangan dan kaki yang menyebabkan 
munculnya rasa sakit. Makanan yang mengandung purin yaitu tempe, jeroan, kerang dan daun melinjo. (Setyawat \& Hartini, 2018)

Aktivitas fisik merupakan suatu pergerakan anggota tubuh yang menyebabkan pengeluaran tenaga yang berguna bagi pemeliharaan kesehatan fisik dan mental, dan mempertahankan kualitas hidup agar tetap sehat.Aktivitas fisik dapat berupa olahraga. Keterbatasan fisik yang dimiliki akibat pertambahan usia dan penurunan fungsi fisiologis pada lansia, maka lansia memerlukan penyesuaian dalam melakukan aktivitas fisik sehari- hari. (Andriyani, 2018)

Menurut asumsi peneliti, hasil ini diperoleh yang dapat menunjukkan pelayanan, fasilitas dan lingkungan UPT yang mendukung kehidupan lansia, yang diketahui kebanyakan biasanya UPT khususnya untuk lansia sangatlah tidak terawat dan tidak terperhatikan. UPT ini sudah menerapkan pelayanan berupa pelayanan cek kesehatan, senam lansia, makanan yang disesuaikan dengan kebutuhan lansia. Kegiatan ataupun aktivitas yang lansia yang didukung oleh UPT, pola makan dan pola istirahat yang menjadikan budaya hidup sehat lansia di UPT baik.

\section{Upaya Pencegahan Penyakit Rematik}

Berdasarkan hasil yang diperoleh diketahui bahwa mayoritas upaya pencegahan penyakit rematik pada lansia di UPT Pelayanan Sosial Lanjut Usia dan Anak Balita Wilayah Binjai dan Medan termasuk dalam kategori baik sebanyak 37 orang $(94,9 \%)$. Hal ini membuktikan bahwasanya pelayanan tenaga kesehatan, fasilitas yang sangat mendukung menyebabkan budaya hidup lansia baik.

Rematik mengakibatkan peradangan pada lapisan dalam pembungkus sendi penyakit ini berlangsung tahunan, menyerang berbagai sendi biasanya simetris, jika radang ini menahun, terjadi kerusakan pada tulang rawan sendi dan tulang otot ligamen dalam sendi. Seseorang yang mengalami rematik mengalami beberapa gejala berikut yakni nyeri sendi, inflamasi, kekakuan sendi pada pagi hari, hambatan gerak persendian (Octa \& Febrina, 2020). Rematik termasuk dalam kelompok penyakit reumatologi yang menunjukkan bahwa kondisi nyeri dan kaku yang menyerang anggota gerak atau sistem musculoskeletal, yaitu sendi, otot, tulang, maupun jaringan disekitar sendi Semua jenis rematik menimbulkan rasa nyeri yang mengganggu. Kemampuan gerak seseorang dapat terganggu oleh adanya penyakit rematik Penyakit yang kronis dapat mengakibatkan gangguan gerak, hambatan dalam bekerja maupun melaksanakan kegiatan sehari-hari sehingga dapat menimbulkan frustasi atau gangguan psikososial penderita dan keluarganya. (Julianda, 2019)

Menurut asumsi peneliti, semakin tua usia, gejala penyakit rematik ini bisa semakin bertambah buruk. Untuk itu, perlu melakukan olahraga teratur dan menjaga berat badan agar artritis tidak memburuk. Jika merasa sakit, sebaiknya istirahat dan jangan memaksa untuk melakukan banyak aktivitas

Hubungan Budaya Hidup Sehat Lansia dengan Upaya Pencegahan Penyakit Rematik

Rematik paling banyak ditemui dan biasanya dari faktor, genetik, jenis kelamin, infeksi, berat badan/obesitas, usia, selain ini faktor lain yang mempengaruhi terhadap penyakit Rematik adalah tingkat pengetahuan penyakit Rematik sendiri memang masih sangat kurang, baik pada masyarakat awam maupun kalangan medis. 
Hasil penelitian diperoleh tidak terdapat hubungan budaya hidup sehat lansia dengan upaya pencegahan penyakit reumatik di UPT Pelayanan Sosial Lanjut Usia Dan Anak Balita Wilayah Binjai dan Medan dengan nilai sig. $0,850>0,05$. Dimana budaya hidup sehat ini adalah olahraga, membersihkan ruangan, bersosialisasi dan kebersihan diri. Disamping ini pelayanan kesehatan di UPT pelayanan sosial sangat didapat oleh lansia. Para lanjut usia selalu mengikuti kegiatan-kegiatan yang berada di UPT pelayanan sosial tersebut. Dan upaya pencegahan pengakit reumatik ini para lansia sering mengikuti penyuluhan di UPT pelayanan sosial yang di adakan para mahasiswa yang mengikuti praktek di UPT itu tersebut. Dan penyakit reumati ini para lansia mengetahui bangaimana pencegahan penyakit tersebut. Dan pola makan lansia sangat diteratur, dan makanan yang dimakan setiap harinya di sediakan oleh UPT pelayanan sosial lanjut usia. Dalam peneliti ini adalah tidak ada hubungan budaya hidup sehat lansia dengan upaya pencegahan penyakit reumatik di UPT Pelayanan Sosial Lanjut Usia Dan Anak Balita Wilayah Binjai Medan dimana budaya hidup sehat lansia di UPT Panti Werda seperti olahraga, polamakan yang teratur, kebersiahan lingkungan yang baik, dan bersosialisasi yang baik.

\section{KESIMPULAN DAN SARAN}

Penelitian ini dapat disimpulkan tidak terdapat hubungan budaya hidup sehat dengan upaya pencegahan penyakit reumatik di UPT Pelayanan Sosial Lanjut Usia Dan Anak Balita Wilayah Binjai dan Medan. Diharapkan kepada lansia yang berumur 60-70 tahun untuk lebih mempertahankan kesehatan lansia dan tenaga kesehatan UPT Pelayanan sosial lanjut usia dan anak balita wilaya binjai medan untuk mempertahankan kesehatan lansia dengan cara mengadakan kegiatan berupa senam lansia, pengecekan kesehatan secara rutin dan promosi kesehatan di masa lansia.

DAFTAR PUSTAKA

Andri, J., Padila, P., Sartika, A., Putri, S. E. N., \& Harsismanto, J. (2020). Tingkat Pengetahuan terhadap Penanganan Penyakit Rheumatoid Artritis pada Lansia. Jurnal Kesmas Asclepius, 2(1), 12-21.

Andriyani, N. A. (2018). Gambaran Faktor Predisposisi dan Presipitasi Kejadian Rheumatoid Arthritis pada Individu yang Hidup di Komunitas. [Skripsi]. Universitas Muhammadiyah Surakarta.

Bawarodi, F., Rottie, J., \& Malara, R. T. (2017). Faktor-faktor yang Berhubungan dengan Kekambuhan Penyakit Rematik di Wilayah Puskesmas Beo Kabupaten Talaud. Jurnal Keperawatan, 5(1).

Julianda, S. V. M. (2019). Hubungan Gaya Hidup dengan Kejadian Reumatik pada Lansia di Puskesmas Ungaran Timur Kabupaten Semarang. [Skripsi]. Universitas Ngudi Waluyo.

Katuuk, M., \& Wowor, M. (2018). Hubungan Kemunduran Fisiologis dengan Tingkat Stres pada Lanjut Usia di Puskesmas Kakaskasen Kecamatan Tomohon Utara. Jurnal Keperawatan, 6(1).

Meliny, M., \& Suhadi, S. (2018). Analisis Faktor Risiko Rematik Usia 45-54 Tahun di Wilayah Kerja Puskesmas Puuwatu Kota Kendari Tahun 2017. (Jurnal IImiah Mahasiswa Kesehatan Masyarakat), 3(2).

Octa, A. R., \& Febrina, W. (2020). Implementasi Evidence Based Nursing Pada Pasien Rematik: Studi Kasus. Real in Nursing Journal, 3(1), 55-60. 
Putri, A. A. (2018). Hubungan Jenis Makanan dan Aktivitas Fisik dengan Kejadian Rematik pada Lanjut Usia di Jorong Padang Bintungan di Wilayah Kerja Puskesmas Koto Baru Kabupaten Dharmasraya Tahun 2017. Menara IImu, 12(6).

Riska Ananda Saputri, P., Bau, A. S., \& Saranani, M. (2017). Kejadian Arthritis Rheumatoid pada Lansia di Panti Sosial Tresna Werdha Minaula Kendari.
[KTI]. Poltekkes Kemenkes Kendari.

Setyawat, V. A. V., \& Hartini, E. (2018). Buku Ajar Dasar IImu Gizi Kesehatan Masyarakat. Yogyakarta: Deepublish.

Syam, S. S. (2016). Faktor-Faktor yang Berhubungan dengan Kejadian Rematik pada Lansia di Wilayah Kerja Puskesmas Mandiangin Tahun 2012. Jurnal Kesehatan, 3(2). 